OAK RIDGE

NATIONAL LABORATORY

MANAGED BY UT-BATTELLE

FOR THE DEPARTMENT OF ENERGY
Metals and Ceramics Division

CRADA Final Report

For CRADA Number ORNL94-0315

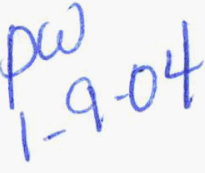

\title{
Reinforcement of Aluminum Castings with Dissimilar Metals*
}

Q. Han and K. L. More

Oak Ridge National Laboratory

M. R. Myers, M. J. Warwick, and Y.C. Chen Cummins Inc.

Date Published - December 2003

Prepared by the

OAK RIDGE NATIONAL LABORATORY

Oak Ridge, Tennessee 37831

Managed by

UT-BATTELLE, LLC

For the

U.S. Department of Energy

Under Contract DE-AC05-00OR22725

APPROVED FOR PUBLIC RELEASE

UNLIMITED DISTRIBUTION

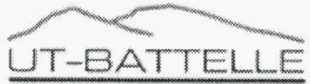

ORNL $27(4.00)$ 


\section{DOCUMENT AVAILABILITY}

Reports produced after January 1, 1996, are generally available free via the U.S. Department of Energy (DOE) Information Bridge.

Web site http://www.osti.gov/bridge

Reports produced before January 1, 1996, may be purchased by members of the public from the following source.

National Technical Information Service

5285 Port Royal Road

Springfield, VA 22161

Telephone 703-605-6000 (1-800-553-6847)

rDD 703-487-4639

Fax 703-605-6900

E-mail info@ntis.fedworld.gov

Web site http://www.ntis.gov/support/ordernowabout.htm

Reports are available to DOE employees, DOE contractors,

Energy Technology Data Exchange (ETDE) representatives, and International Nuclear Information System (INIS)

representatives from the following source.

Office of Scientific and Technical Information

P.O. Box 62

Oak Ridge, TN 37831

Telephone 865-576-8401

Fax 865-576-5728

E-mail reports@adonis.osti.gov

Web site http://www. osti.gov/contact.htm!

This report was prepared as an account of work sponsored by an agency of the United States Government. Neither the United States Government nor any agency thereof, nor any of their employees, makes any warranty, express or implied, or assumes any legal liability or responsibility for the accuracy, completeness, or usefulness of any information, apparatus, product, or process disclosed, or represents that its use would not infringe privately owned rights. Reference herein to any specific commercial product, process, or service by trade name, trademark, manufacturer, or otherwise, does not necessarily constitute or imply its endorsement, recommendation, or favoring by the United States Government or any agency thereof. The views and opinions of authors expressed herein do not necessarily state or reflect those of the United States Government or any agency thereof. 
Metals and Ceramics Division

CRADA Final Report

for CRADA Number ORNL94-0315

\title{
Reinforcement of Aluminum Castings with Dissimilar Metals ${ }^{*}$
}

\author{
Q. Han and K. L. More \\ Oak Ridge National Laboratory \\ and \\ M. R. Myers, M. J. Warwick, and Y.C. Chen \\ Cummins Inc. \\ Date Published - December 2003 \\ Prepared by the \\ OAK RIDGE NATIONAL LABORATORY \\ Oak Ridge, Tennessee 37831 \\ managed by \\ UT-BATTELLE, LLC \\ for the \\ U.S. Department of Energy \\ under Contract DE-AC05-00OR22725 \\ APPROVED FOR PUBLIC RELEASE \\ UNLIMITED DISTRIBUTION
}

* This work was supported through a CRADA with Cummins Inc., sponsored by the U.S. Department of Energy, Assistant Secretary for Energy Efficiency and Renewable Energy, Office of Transportation Technology, Lightweight Vehicle Materials Program, under contract DE-AC05-00OR22725 with UT-Battelle, LLC. 


\section{Abstract}

The project "Reinforcement of Aluminum Casting with Dissimilar Metal" was a Cooperative Research and Development Agreements (CRADAs) between Oak Ridge National Laboratory (ORNL) and Cummins Inc. This project, technologies have been developed to reinforce aluminum castings with steel insert. Defect-free bond between the steel insert and the aluminum casting has been consistently obtained. The push-out experiment indicated that the bond strength is higher than that of the Al-Fin method. Two patents have been granted to the project team that is comprised of Cummins Inc. and ORNL. This report contains four sections: the coating of the steel pins, the cast-in method, microstructure characterization, and the bond strength. The section of the coating of the steel pins contains coating material selection, electro-plating technique for plating $\mathrm{Cu}$ and $\mathrm{Ni}$ on steel, and diffusion bonding of the coatings to the steel. The section of cast-in method deals with factors that affecting the quality of the metallurgical bond between the coated steel and the aluminum castings. The results of microstructure characteristics of the bonding are presented in the microstructure characterization section. A push-out experiment and the results obtained using this method is described in the section of bond strength/mechanical property.

\section{Statement of Objectives}

The objective of the project was to develop a framework for the production of aluminum alloy castings reinforced with dissimilar metals, and to produce a metallurgical bond between the steel inserts and the aluminum casting for superior interfacial strength and heat transfer characteristics. The technology to be developed had to be different to that of Al-Fin method which involves dip coating of steel insert in molten metals of low melting temperatures (such as zinc or aluminum alloys) and cast in the coated steel in aluminum castings. As a result, materials with higher melting temperatures than that of aluminum were chosen for the coating layers on the steel inserts.

\section{Benefits to the Funding DOE Office's Mission}

The development of effective bonds between aluminum castings and steels is important to significantly decrease the weight of heavy duty diesel engines, thus improving handling, fuel economy, and payload. The project will benefit DOE OTT in meeting goals of the National Energy Strategy through improved energy efficiency and improved worldwide competitiveness of U.S. industry.

\section{Technical Discussion of Work Performed by All Parties}

The project "Reinforcement of Aluminum Casting with Dissimilar Metal" was a Cooperative Research and Development Agreements (CRADAs) between Oak Ridge National Laboratory (ORNL) and Cummins Inc. The ORNL participants were Drs. K. L. More, S. Viswanathan, and Q. Han. Other people involved in this project were R. Subramanian, E. Kenik, E. Hatfield, 
C. Stevens, L. Walker, T. Geer, and D. N. Braski. During the executions of the project, quarterly meetings were held regularly to review experimental results. A large amount of data were generated and circulated in the review meetings. The main technical achievements are described in the following sub-sections.

\subsection{The Coating of Steel Pin}

\subsubsection{Coating material selection}

Sacrificial coatings were designed in order to prevent the steel insert from contamination and, more importantly, from the formation of unfavorable intermetallic phases. Coating materials considered were $\mathrm{Cu}, \mathrm{Ni}, \mathrm{Ag}$, and $\mathrm{Cr}$. In the early stages of the project, a single layer coating using each of the above materials was tested. Later, it was decided to use a multiple layer coating (two layer) on the steel insert. The thickness of each coating layer is between 1 to 4 mils. The steel inserts were made of 1144 steel. The sizes of the inserts were 2 in. long and $0.5 \mathrm{in}$. in diameter. The selection criteria for the materials used for the multiple layer coating are:

- The material used for the outer layer coating should have a larger thermal expansion coefficient than that used as the inner layer. Both coating materials should have larger thermal expansion coefficient than steel. This is to ensure that the coatings can physically bond to the steel during cooling.

- The coating materials should have large solubility between each other and the material used as the inner coating should have a large solubility in steel. This is to ensure that the coatings can chemically bond to each other during diffusion bonding.

- The outer layers act as a sacrificial coating to help bonding between the inner layer and the aluminum casting.

Based on the above three criteria, two steel coating systems were selected. They were steel $/ \mathrm{Ni} / \mathrm{Cu}$ and steel $/ \mathrm{Ni} / \mathrm{Ag}$. Both systems were tested but the research was focused on the steel/Ni/Cu system.

\subsubsection{Electro-plating technique}

Electro-plating techniques were used to plate multiple layer coatings on steel inserts. Initially, the commercial techniques of electro-plating were used. After the nickel layer was plated at $170^{\circ} \mathrm{F}$, the hot steel inserts were immediately dipped in solutions at room temperature for coating the copper layer. Optical microscopy revealed that a gap was formed at the $\mathrm{Ni} / \mathrm{Cu}$ interface shown in Figure 1. It was concluded that the gap was formed during $\mathrm{Cu}$ coating. When the hot insert was dipped into the electrolytic liquid at room temperatures, a thin layer of copper was formed immediately on top of the nickel layer. In the mean time, the hot steel insert with a layer of nickel coating contracted during cooling, leaving behind a gap at the $\mathrm{Ni} / \mathrm{Cu}$ interface.

Based on the understanding of the gap formation, the electro-plating technique was modified. After Ni was plated, the inserts were cooled to room temperature. The copper layer was then coated at $110 \mathrm{~F}$. Figure 2 shows the steel $/ \mathrm{Ni} / \mathrm{Cu}$ interfaces using the modified plating technique. No gap was found between steel/Ni/Cu layers. Less pores were found in the coated layer after diffusion bonding. In order to strengthen the interface of steel/ $\mathrm{Ni}$, the plating technique was 
further modified. The steel surface was deep etched to make the surface rougher. The final electro-plating technique is as following:

- Soak cleaning and degrease

- Remove rust on steel surface using $30 \% \mathrm{HCl}$ acid

- Deep etch the insert surface using $50 \% \mathrm{HCl}$ at $104^{\circ} \mathrm{F}$

- Plate Ni at $170^{\circ} \mathrm{F}$

- Rinse in tap water at room temperature

- Dip in $30 \% \mathrm{HCl}$ at room temperature

- Rinse in tap water at room temperature

- Plate $\mathrm{Cu}$ at $110^{\circ} \mathrm{F}$

- Rinse in tap water at room temperature

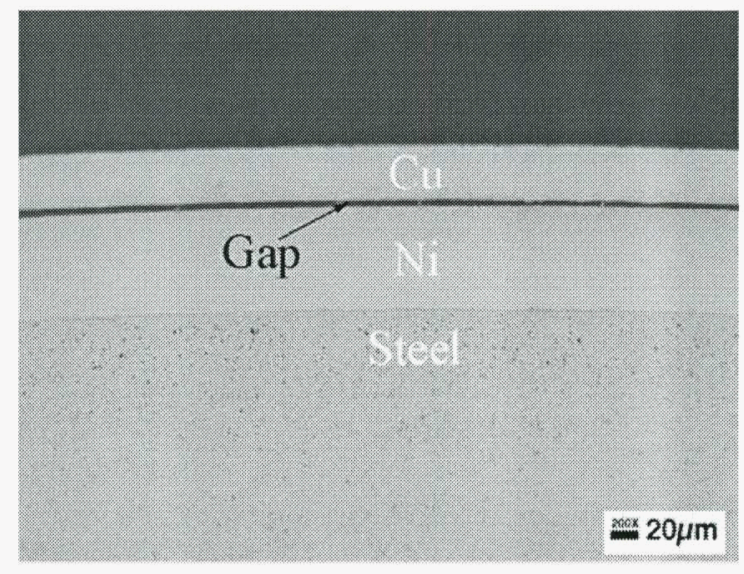

Figure 1. A gap was formed at the $\mathrm{Ni} / \mathrm{Cu}$ interface when the nickel and copper layers were coated using the commercial electro-plating techniques.

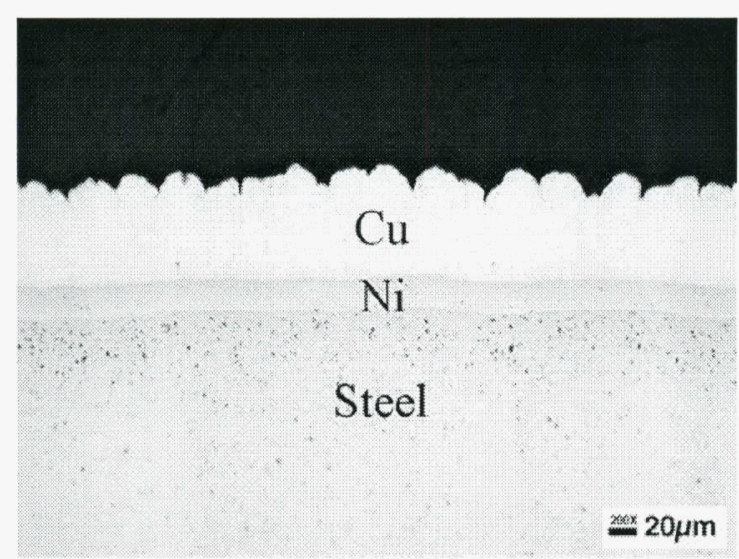

Figure 2. The modified coating technique results in better bonding between the nickel and copper layer. No gap was found at $\mathrm{Cu} / \mathrm{Ni}$ and steel/Ni interfaces. 


\subsubsection{Diffusion bonding}

The electro-plated coating layers were then diffusion bonded. The coated inserts were loaded in the vacuum furnace at room temperature, heated to $900^{\circ} \mathrm{C}$, held at $900^{\circ} \mathrm{C}$ for 4 hours, and furnace cooled to room temperatures. During diffusion bonding, atoms in the neighboring layers diffuse into each other, forming a diffusion bond. Figure 3 shows the composition profiles in the steel substrate and the two coating layers. Ni diffuses into both of the steel substrate and the $\mathrm{Cu}$ layer. No iron or copper atoms have penetrated the nickel layer.

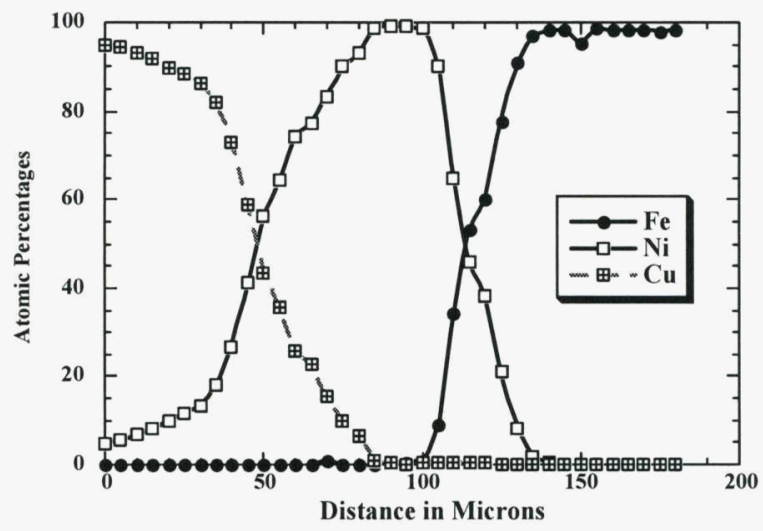

Figure 3. The composition profiles in the copper (left), nickel (middle), and steel (right) layers after diffusion bonding at $900^{\circ} \mathrm{C}$ for 4 hours.

\subsection{The Cast-In Method}

\subsubsection{The method}

After diffusion bonding, the coated inserts were cast in place using a sand mold. Figure 4 illustrates the location of the steel inserts in a casting. Three castings were linked by the runners and in-gates. There were two inserts in each casting cavity.

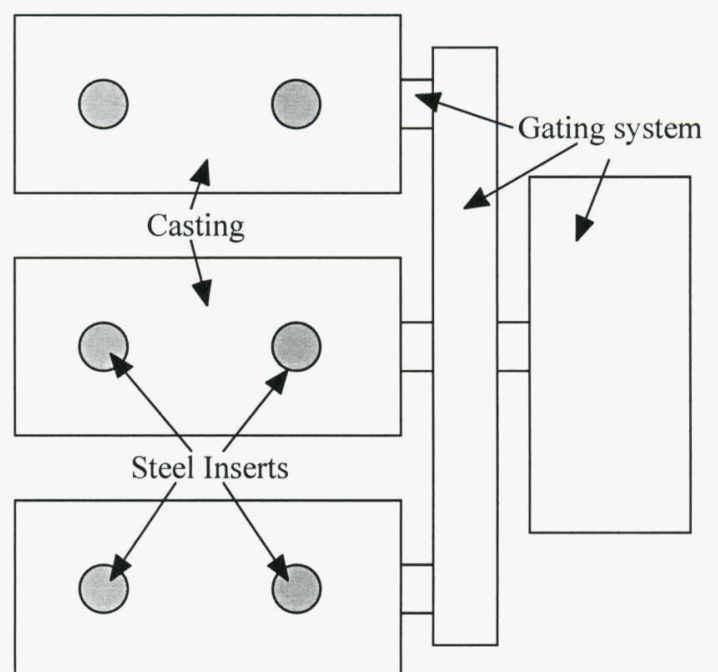

Figure 4. Schematic illustration of the locations of steel inserts in castings. 
The procedure for casting of steel inserts in place given below:

- Dry the sand mold for 6 hours using heat lamps

- Pre-heat the coated inserts at $120^{\circ} \mathrm{C}\left(250^{\circ} \mathrm{F}\right)$ for $15 \mathrm{~min}$.

- Melt and maintain aluminum alloy A354 at $720^{\circ} \mathrm{C}$

- Degas the melt at $720^{\circ} \mathrm{C}$ for $30 \mathrm{~min}$. using argon $+4 \%$ chlorine

- Add 0.375 wt.\% Sr and 0.5 wt.\% grain refiner before pouring

- Place two preheated, coated steel inserts in each mold cavity

- Pour the melt into the mold under the protection of argon

- Over flow the flow head to ensure no dirty melt freezes on the steel inserts

\subsubsection{Factors affecting the quality of the bond}

The quality of the bond between the steel insert and the casting can be affected by many factors such as the melt quality, hydrogen content in the melt, pour temperature, the pour time, the temperature of the mold and the steel insert, the moisture content of the mold, the protective atmosphere during casting, and the quantity of melt flowing pass the inserts. Some of the parameters cannot be altered much for a given casting. The most important factors that affect the quality of the bond are hydrogen content in the melt and over flow (to ensure that no dirty melt freezes on the inserts).

\section{Hydrogen Content}

Figure 5 shows the influence of hydrogen on the quality of the steel/aluminum bond. Without sufficient degassing, a substantial amount of porosity occurred at the steel/casting interface shown in Figure 5. The bond quality was improved with increasing degassing. When the hydrogen level in the melt was reduced further, defect-free bond was obtained. Experimental results indicated that, in order to obtain defect-free bond, the hydrogen level in the melt had to be such that no porosity could be observed with naked eyes at the center of a RPT (Reduced Pressure Test) specimen cut using a bench saw. The melt has to be cast in argon atmosphere to prevent it from picking up hydrogen during mold filling process.

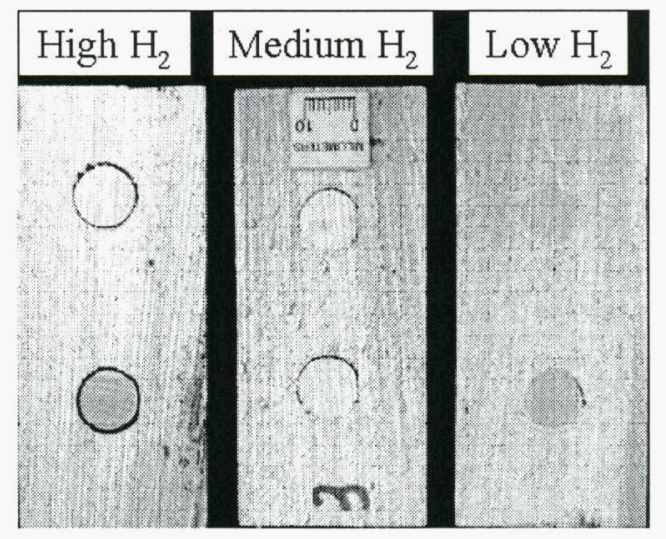

Figure 5. The effect of hydrogen content on the quality of bond between the steel insert and the casting. The bond is defective when the hydrogen level in the melt is high. 


\section{Over Flow}

During mold filling process, the flow head collects oxide and loose sand as it flow through the mold surfaces. It also absorbs hydrogen from the moisture in the mold. To prevent the flow head from freezing on the steel inserts, an over flow was designed. The use of over flow also allowed a sufficient quantity of melt to flow pass the inserts. In case the flow head freezes on the inserts, the subsequent melt can re-melt the frozen flow head and take it away from the steel inserts.

\subsubsection{The quality of the insert/casting interface}

Having identified the factors that affect the quality of the steel/casting interface, the procedure given in section 2.1 was developed and tested. Figure 6 shows the quality of the bond at the center of three castings (containing 6 steel inserts). No defect was observed at the steel/casting interface under microscope. Although some kinds of defects on the steel/casting were observed within a few millimeters near the surface of the casting, the defective regions can be easily removed by machining. The defective regions can also be moved out of the casting for easy machining operations.
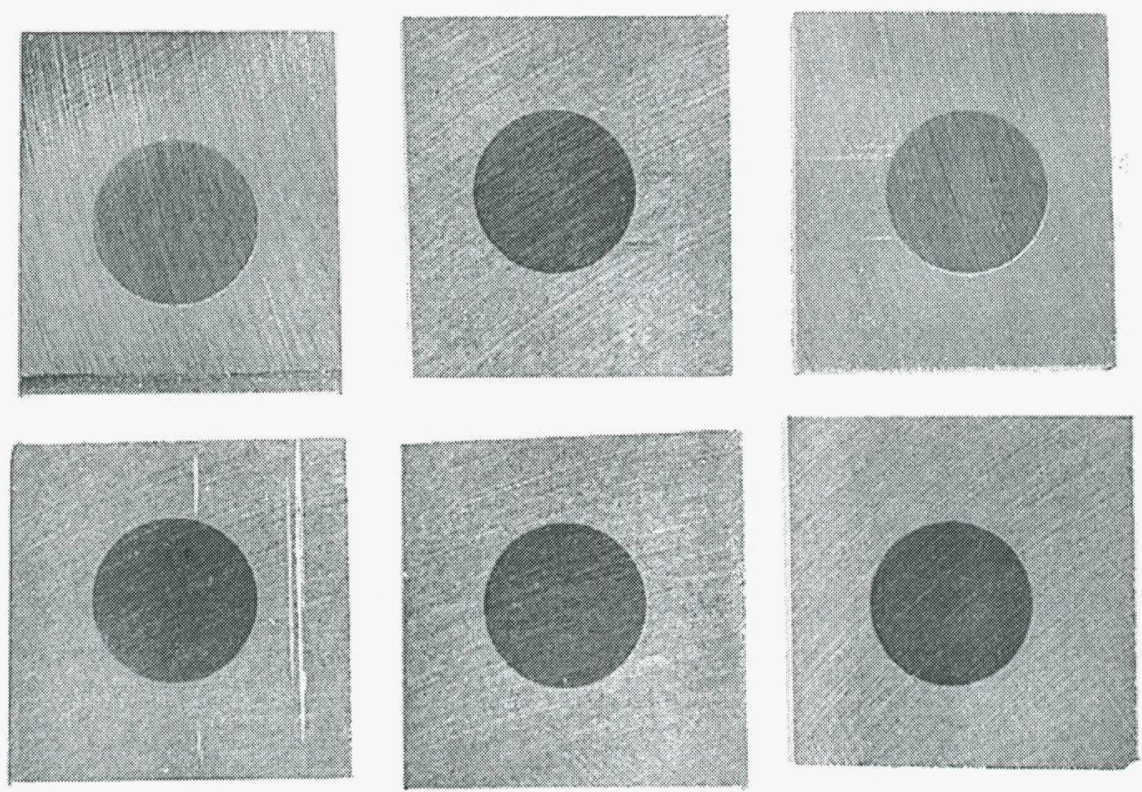

Figure 6. Defect-free bond obtained in casting by careful degassing and protection using argon atmosphere during casting.

\subsection{The Bond Strength}

\subsubsection{The push-out experiments}

Samples illustrated in Figure 7 were cut for testing the mechanical properties of the steel/casting bond. A push-out test setup, shown in Figure 8, was designed to evaluate the interfacial strength of the bond. A punch ( 0.375 in. diameter) was used to push-out a steel insert ( 0.5 in. diameter) out of the aluminum alloy. Set screws were used for alignment. The specimen dimensions were 1 " square and $1 / 4^{\prime \prime}$ thick with $1 / 2^{\prime \prime}$ diameter steel insert at the center. Five specimens were cut 
using a bench saw from one steel insert (1.5" in height). The crosshead speed was $0.05 \mathrm{in} . / \mathrm{min}$. The peak stress on the stress/displacement curve was defined as the interfacial strength of the bond.

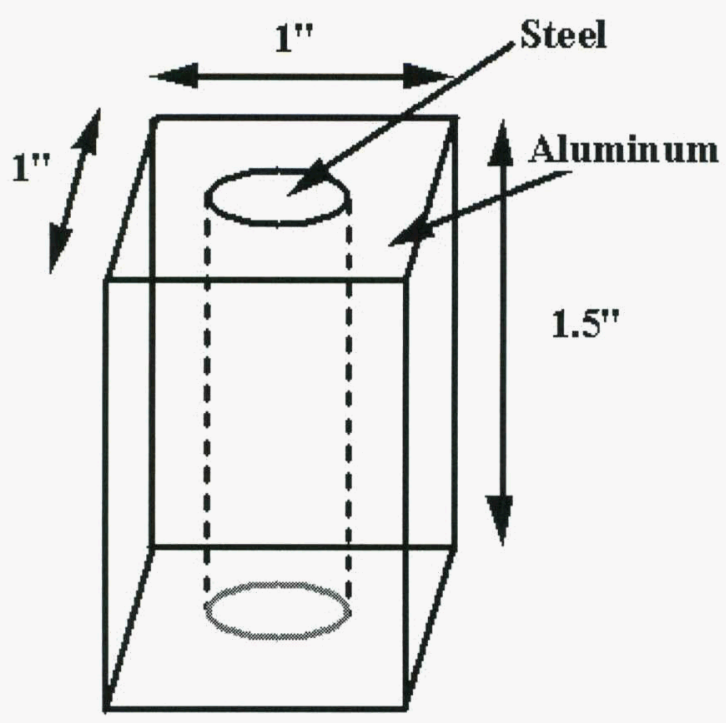

Figure 7. Schematic illustration of the geometry of the sample cut from a casting.

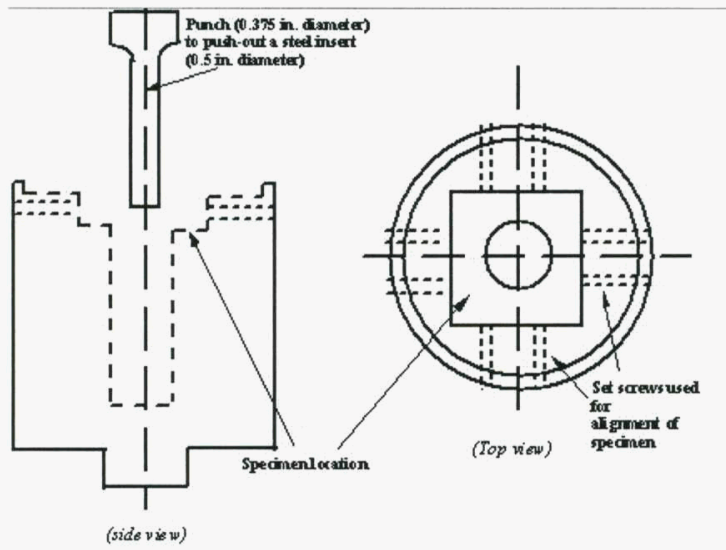

Figure 8. Schematic illustration of the setup for the push-out experiments.

\subsubsection{Bond strength under as-cast conditions}

Push-out experiments were carried out to investigate the strength of steel/casting bond under various conditions. These conditions included the thickness of nickel coating (1 to 3 mils with an outer layer copper coating of 4 mils) and diffusion bonding times ( 1 to 4 hours at $900^{\circ} \mathrm{C}$ ). Figure 9 shows the interfacial strength as a function of nickel thickness and diffusion bonding time under as-cast conditions. The bond strength is between 8,000 to 12,000 psi, higher than that of the Al-Fin (7,200 psi). The data suggest that the bond strength is not affected by the diffusion bonding time in the range between 1 to 4 hours. The bond strength is hardly affected by the thickness of nickel coating in the range between 0.5 to 2.5 mils. 


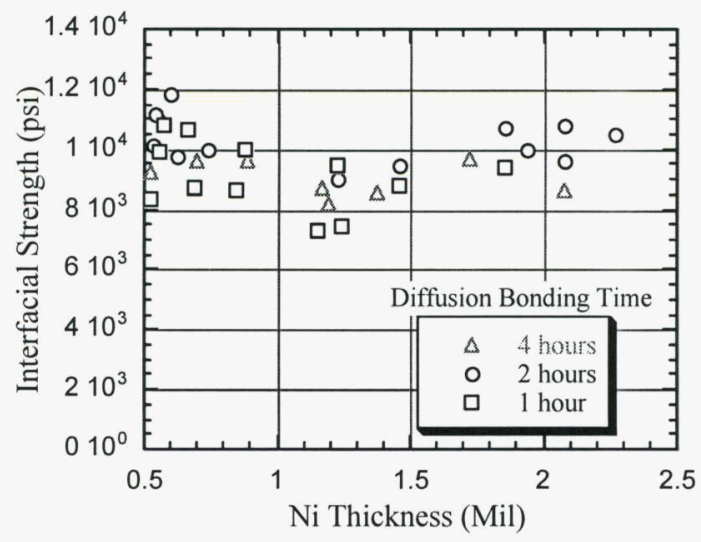

Figure 9. The relationship between the measured bond strength, the thickness of nickel plating, and the diffusion bonding time. High bonding strength has been achieved under as-cast conditions.

\subsubsection{Bond strength after $\mathrm{T} 5$ or $\mathrm{T} 6$ heat treatment}

Bond strength after heat treatment was also measured. Figure 10 show a comparison of the ascast bond strength with that after T5 heat treatment (held at $150^{\circ} \mathrm{C}$ for 10 hours). The as-cast bond strength is not affected by T5 heat treatment.

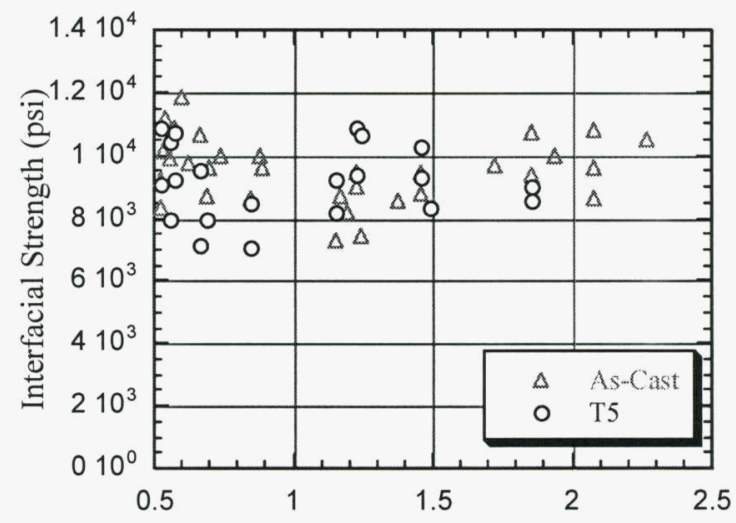

Figure 10. A comparison of bond strength under as-cast conditions with that after T5 heat treatment. The as-cast bond strength is not affected by T5 temper.

The castings were then heat treated under the T6 conditions (held $526^{\circ} \mathrm{C}$ for 10 hours, quenched to $71^{\circ} \mathrm{C}$, and then held at $150^{\circ} \mathrm{C}$ for 10 hours). After T6 heat treatment, specimens were cut using a bench saw from the castings and tested for the bond strength. Figure 11 shows a comparison of the as-cast bond strength with that after T6 heat treatment. The interfacial strength measurement showed that T6 heat treatment did not reduce the bond strength significantly. This indicated that castings with steel inserts can be safely T6 heat treated. 


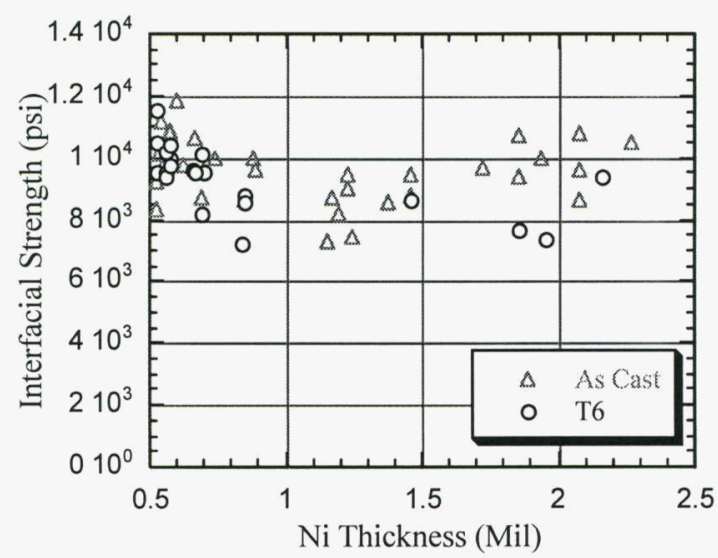

Figure 11. A comparison of bond strength under as-cast conditions with that after T6 heat treatment. The as-cast bond strength is not reduced by T6 temper.

\subsection{Microstructure Characterization}

The microstructure near the steel/aluminum bond was carefully characterized. Figure 12 shows the microstructure of the steel/casting interface and the locations where the micro-hardness (I to III) and micro-compositions (1 to 7) were measured. Between steel and the aluminum casting, two layers of intermetallics, marked layer 1 and layer 2 respectively, were observed. The thickness of layer 2 increases with increasing thickness of the nickel coating.

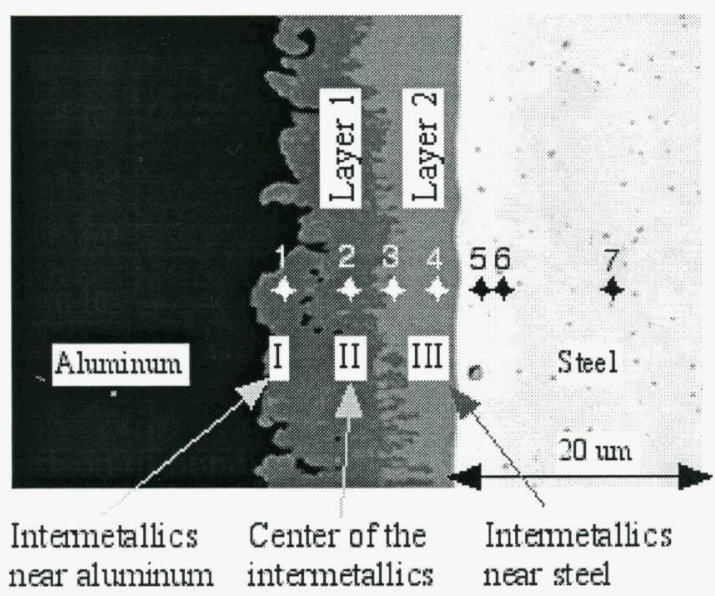

Figure 12. Schematic illustration of the locations for the measurements of composition and hardness across the bond between steel and the aluminum casting.

The compositions at each of the locations (marked from 1 to 7 ) on Figure 12 are given in Table 1 under two conditions: 1 mil nickel coating (1Ni) and 4 mil nickel coating (4Ni). The inserts were diffusion bonded at $900^{\circ} \mathrm{C}$ for 4 hours. Note that locations marked with 1 to 4 correspond to that on the intermetallic layers. Table 1 shows that the intermetallics contain less iron and silicon but more nickel, copper, and aluminum with a 4 mil nickel coating than that with 1 mil nickel coating. 
Table 1. The composition (wt.\%) distribution across the steel/aluminum bond.

\begin{tabular}{|c|c|c|c|c|c|c|c|c|c|c|}
\hline \multirow{2}{*}{ Location } & \multicolumn{2}{|c|}{ Fe } & \multicolumn{2}{c|}{ Ni } & \multicolumn{2}{c|}{ Cu } & \multicolumn{3}{c|}{ Al } & \multicolumn{3}{c|}{ Si } \\
\cline { 2 - 11 } & $1 \mathrm{Ni}$ & $4 \mathrm{Ni}$ & $1 \mathrm{Ni}$ & $4 \mathrm{Ni}$ & $1 \mathrm{Ni}$ & $4 \mathrm{Ni}$ & $1 \mathrm{Ni}$ & $4 \mathrm{Ni}$ & $1 \mathrm{Ni}$ & $4 \mathrm{Ni}$ \\
\hline 1 & 26.5 & 11.9 & 1.2 & 19.4 & 0.2 & 2.5 & 58.0 & 66.1 & 14.5 & 2.4 \\
\hline 2 & 26.0 & 12.2 & 2.0 & 19.1 & 0.3 & 0.8 & 58.0 & 65.2 & 14.0 & 2.6 \\
\hline 3 & 22.5 & 15.5 & 1.2 & 21.3 & 0.8 & 2.6 & 56.0 & 53.2 & 14.5 & 7.4 \\
\hline 4 & 29.0 & 18.5 & 4.0 & 20.4 & 1.5 & 2.4 & 56.0 & 50.9 & 9.5 & 7.9 \\
\hline 5 & 85.0 & 55.5 & 14.5 & 43.8 & 0.0 & 0.4 & 0.3 & 0.3 & 0.2 & 0.0 \\
\hline 6 & 95.4 & 83.4 & 4.6 & 16.6 & 0.0 & 0.0 & 0.0 & 0.0 & 0.0 & 0.0 \\
\hline 7 & \multicolumn{9}{|c|}{100.0} \\
\hline
\end{tabular}

The micro-hardness of the phases near the bond was measured and illustrated in Figure 13. The hardness of the intermetallic phases is much higher than that of aluminum alloy and steel. A large number of hardness measurements of the intermetallic phases was carried out to investigate the effect of the nickel coating thickness on the hardness of the intermetallics. The results indicated that the hardness was not affected by the thickness of the nickel coating.

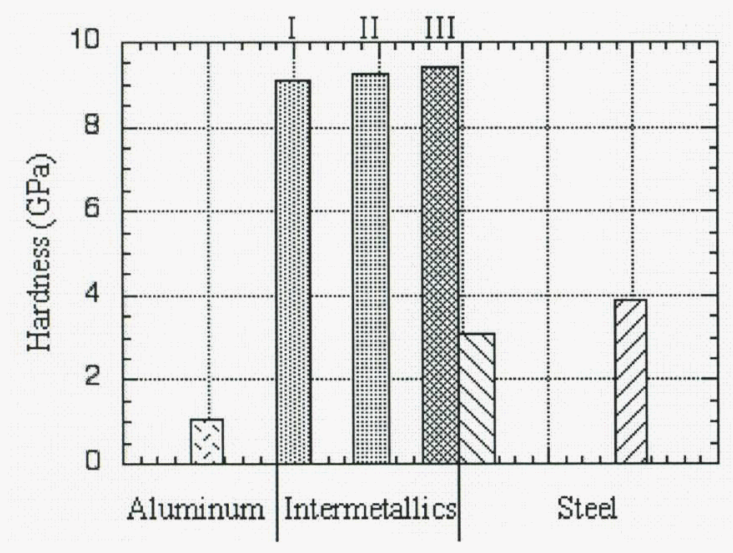

Figure 13. The micro-hardness distribution across the steel/aluminum bond. The locations of I, II, and III are illustrated in Figure 12.

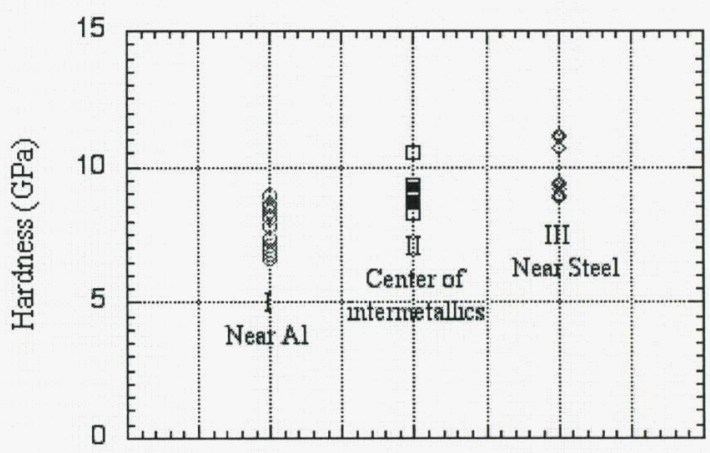

Figure 14. The micro-hardness of the phases in the bond between steel and aluminum casting. The locations of I, II, and III are illustrated in Figure 12.

A comparison of the hardness in the intermetallic layers is shown in Figure 14. The closer to the steel, the higher the micro hardness of the intermetallic phases. This indicated that the micro hardness of the intermetallic phases increases with increasing iron concentration. 


\section{Subject Inventions}

The subject inventions led to two patents as follows:

Martin R. Myers, Michael J. Warwick, Y.C. Chen, R. Subramanian, S. Viswanathan, K. More, and Q. Han, "Metallurgical Bonding of Inserts Having Multi-Layered Coatings within Metal Casting," Patent Number US 6,443,211 B1, September 3, 2002.

Martin R. Myers, Michael J. Warwick, Y.C. Chen, R. Subramanian, S. Viswanathan, K. More, and Q. Han, "Metallurgical Bonding of Coated Inserts Within Metal Castings," Patent Number US 6,484,790, November 26, 2002.

\section{Commercialization Possibilities}

Two patents have been awarded to the research team and the industrial partners. Cummins Inc. is working on commercialization possibilities of the developed technologies.

\section{Plan for Future Collaboration}

Further research is needed for reinforcement of aluminum castings with large steel inserts or inserts made of other materials, such as cast irons or superalloys. The further collaboration is dependant on available DOE funding.

\section{Conclusions}

A methodology has been developed to produce defect-free bond between steel and aluminum alloy using the cast-in method, which is the most economic way of reinforce aluminum part with steel inserts. The strength of the bond obtained is better than the tradition Al-Fin method. 